\title{
Social Media and Global Development Rituals: a content analysis of blogs and tweets on the 2010 MDG Summit
}

\author{
Tobias Denskus and Daniel E Esser
}

\begin{abstract}
Social media content generated by web logs ('blogs') and Twitter messages ('tweets') constitute new types of data that can help us better understand the reproduction of global rituals in the context of international development policies and practice. Investigating the United Nations High-level Plenary Meeting of the General Assembly on the Millennium Development Goals (MDGS), a three-day event held at UN Headquarters in New York in 2010, as a case study, we examine a sample of 108 blog entries discussing the meeting, as well as 3007 related tweets. We find that topics receiving the densest coverage mirrored existing priorities as defined by the MDGS. Although most blog entries created content which, in contrast to tweets, went beyond spreading mere factual or referential information on the event and even included some critical commentary, sustained debates did not emerge. Our findings suggest that social media content accompanying the Summit reproduced global development rituals and thus failed to catalyse alternative priorities for and approaches to international development.
\end{abstract}

On a global scale, web log entries ('blogs') and messages sent to personalised networks of followers through a virtual platform run by Twitter, Inc ('tweets') create gigabytes of new data per hour. While bloggers began posting commentary on the internet in the late 1990s, tweets only hit cyberspace in July 2006. Only a few years later, however, both media are common means of sharing opinions and updates for individuals as well as for businesses, governments and nongovernmental organisations (NGOs) active in the field of international development. Yet research on the use of social media in the context of international development has so far been limited in scope. Research on the use of tweets has focused on how these media can influence crisis politics, 1 particularly in the aftermath of the "Arab Spring',2 as well as their potential for development programming, 3 but not on their role in either sustaining or changing dominant discourses. The only body of research focusing on the use of Twitter in conference settings has been limited to smaller, primarily academic gatherings.4 With regard to blogs and development, only one study so far has investigated this nexus by gauging the impact of development economics blogs on economic policies.5 In light of this empirical dearth, we seek to demonstrate that incorporating analyses of social media content into research on global conferences is a promising avenue for understanding the reproduction of international development policy more broadly. At the same time our paper also provides an opportunity to critically appraise recent assertions that social media have contributed to the formation and sustenance of a global civil society. 6 By focusing on social media coverage of the 2010 United Nations High-level Plenary Meeting of the General Assembly on the Millennium Development Goals (MDG Summit) in New York, we present an empirical case and explore its ramifications for the reproduction of global rituals in international development practice.

At the centre of global conferences, whether the UN Conference on Environment and Development in Rio de Janeiro (Earth Summit) in 1992 or the 2010 MDG Summit, lies a shared interest among national governments to define common ground with respect to 
pressing global challenges and to confirm political priorities and potential financial commitments to address them. By magnifying the emergence and sustenance of issues around which global social movements galvanise and act, such global conferences also forge 'collective experiences... which to their international participants, organizations and networks constitute learning processes'.7 In other words, conferences are not only diplomatic focal points but also serve as vehicles through which epistemic communities create shared discourses and thus maintain their identity and cohesion. Whereas resolutions from the 1992 Earth Summit were disseminated via television, fax and telephone, global conferences today use the internet as their major strategic communication platform to facilitate instantaneous information flows. Although internet access in many countries is not universally available, opportunities for conference outsiders to stay abreast of the latest developments during such events are better than ever before. A central question, however, is whether communication, in the context of global conferences, is limited to conference organisers and participants transmitting information to passive receivers. The ascent of social media during recent years has made it possible to create and utilise virtual spaces of participatory communication that can, theoretically at least, reinforce or redefine the discourses emanating from global conferences. Especially in light of the 2010-11 Arab Spring and its use of social media, we must ask whether social media can produce a similar momentum at critical junctures of global policy emergence. In order to examine this potential, we first posit the MDG Summit as both a virtual and physical research site. We then provide an overview of the literature on the ritualistic quality of global conferences and explain how we approached the analysis of content generated by two different types of social media. We investigate our research question by examining a sample of 108 blog entries published on 34 different blogs, as well as 3007 real-time tweets linked both substantively and temporally to the Summit. We discuss our findings along three analytical dimensions and, in conclusion, relate our specific observations on the content of social media coverage of the MDG Summit to the larger debate on the discursive reproduction of global policy frameworks in the context of international development policy and practice.

\section{The 2010 MDG Summit: the success of 'exceptionally boring meetings'}

The 2010 MDG Summit took place from 20 to 22 September in New York. High-level roundtable discussions addressed critical global development challenges such as poverty, hunger, gender equality, health, education, sustainable development, the special needs of the most vulnerable, and the establishment of lasting partnerships.8 In addition to discussions in the UN General Assembly, over 80 so-called partnership events were held, and several key stakeholders seized the opportunity to announce strategic initiatives aimed at achieving the objectives set forth in the MDGS.9 UN Secretary General Ban Ki-Moon unveiled a \$40 billion strategy for improving the health of women and children,10 and the meeting's officially proclaimed achievements also included affirming the General Assembly's commitment to the target completion date of 2015, as well as securing pledges of financial support for each of the eight MDGS.11 Remarks by participating heads of state generally praised the progress made toward achieving the MDGS, acknowledged areas still requiring improvement, enumerated aspects of their country's contributions to the effort and, in some cases, also offered muted criticism of select issues. US President Barack Obama, for 
example, outlined his administration's policy on development and connected progress on the MDGS to the fulfilment of the Universal Declaration of Human Rights.12 British Deputy Prime Minister Nick Clegg advanced the case that international development was squarely in the interests of the UK and pointed to the Summit as an opportunity for donor and recipient nations to establish clear understandings of their partnerships.13 The Russian Foreign Minister, Sergey Lavrov, highlighted the UN's unique position for coordinating the international push to eliminate poverty and noted his country's increasing efforts to contribute to that goal.14

Somewhat in contrast to the majority of official statements, and in parallel to emphasising the achievements of his own country, India's Minister of External Affairs also recognised the setbacks in progress on the MDGS and welcomed Secretary General KiMoon's initiative to address the 'forgotten MDGS' related to women and children's health.15 The Chinese representative, Premier of the State Council Wen Jiabao, emphasised China's achievements in lifting its own population out of poverty and the degree to which this trend had contributed towards achieving the first MDG.16 Similarly the Brazilian Minister for Social Development, Marcia Lopez, emphasised her own country's role in South-South partnerships while noting the need to honour and increase financial commitments if the target date of 2015 was to remain a possibility.17

Other public figures and media stars were highly visible during the event as well. Melinda French Gates, co-chair of the Bill and Melinda Gates Foundation, addressed the UN General Assembly and encouraged those present not to look at the progress towards the MDGS in terms of total success or total failure. She urged delegates not to allow impatience in pursuing the MDGS to overpower the optimism implicit in these goals, citing advances already made and new commitments launched during the Summit.18 An active commentator from the Global South, Queen Rania of Jordan, used the Summit to promote education, one of the key issues the MDGS cover.19 Jeffrey Sachs, professor at Columbia University and one of the most fervent promoters of the MDGS, described the Summit as an opportunity to cut through the noise of everyday affairs and to focus on the challenges of development.20 While acknowledging the difficulties of establishing effective funding streams and coping with fractured, individual donor agendas, he argued that the MDG Summit and its associated reporting mechanisms had succeeded in keeping crucial development challenges on the global agenda. Finally, quipping that the Summit had been 'three or four long days of exceptionally boring meetings',21 singer Bob Geldof also emphasised that it had succeeded in taking stock of the progress of the MDGS up to that point and had outlined further steps for advancing the causes represented within them.

\section{Global conferences as discursive rituals}

Reflecting on global conferences, Long has argued that such mega-events have become part of the process of 'knowledge production, dissemination and transformation' in global politics, multilateral organisations and constructivist analysis of international relations.22 Global conferences are thus part of the discursive development repertoire that includes meetings and consultancy missions,23 the outputs of these undertakings such as consultancy reports or evaluations24, as well as the work, lifestyles and habitus of international development personnel.25 Chabbott's observations from the 1990 World Conference on Education 
for All, although stemming from the pre-digital era, can still be considered a blueprint for understanding global summits on international development:

[EFA] in some ways mimicked a recipe already established in other sectors by earlier world conferences. EFA organizers used the [UN] Declaration of Universal Human Rights and other existing declarations as a basis for drafting a declaration and plan of actions couched in terms of human rights so often repeated that no nation state could resist the invitation to accept by acclamation. The recipe provided for a series of follow up meetings and conferences to reiterate goals, publicize progress—or lack of it—thus applying normative pressure to nation states and

organizations.26

Unsurprising in light of these observed dynamics,27 the UN officially regards global conferences as important tools to 'shape our global future'.28 Little's conclusion from ethnographic research at the 1992 Earth Summit captures this centrality when he characterises them as 'an increasingly important part of the modern world [which] have diverse meanings and impacts'.29 At the same time Little also points to their role 'as forums for the creation of a new political cosmology and the mystification of crude power politics'.30 Both aspects are elaborated further in Lechner and Boli's work.31 Echoing Rothenbuhler's definition of rituals as 'the voluntary performance of appropriately patterned behaviour to symbolically effect or participate in the serious life',32 as well as Bauman's conceptualisation of performance as 'an aesthetically marked and heightened mode of communication, framed in a special way and put on display to an audience', 33 Lechner and Boli describe global conferences as:

a secular ritual by periodically focusing world attention on selected topics through events in a particular format that lead to the affirmation and promulgation of knowledge and principles guiding global action. As part of a larger whole, they have helped to make culture that transcends regional traditions. Enshrining certain ideas and symbols as 'totems' of world society, they have contributed to defining a global reality.34

The genealogy of the MDGS is a telling vignette illustrating the ritual power of global conferences. Jan Vandemoortele, a long-time staff member of the United Nations Development Programme (UNDP) and one of their key intellectual architects, has argued that 'the MDGS were not developed from scratch; they resulted from an incremental, and sometimes piecemeal, process of generating a political consensus on the major elements of the development agenda-mostly through a series of world summits and international conferences in the 1990s.35 However, Hulme and Fukuda-Parr's research, based on expert interviews with senior international bureaucrats, paints an entirely different picture, one that focuses on global conferences' performative role.36 Instead of forging a negotiated political consensus, Hulme and Fukuda-Parr outline a process driven by a few senior policy makers who dominated the agenda-setting process:

The process to develop the 'final' MDG list...was undertaken by an ad hoc group, headed by the UN Secretariat's Michael Doyle...Key figures in this ad hoc group were not the leaders of the official UN statistical world, whose efforts could be lauded and then set aside. Instead, they were the World Bank's Eric Swanson, OECD-DAC's Brian Hammond, and UNDP's Jan Vandemoortele. All had worked together on the IDG [1996 International Development Goals] monitoring document, 2000: A Better World For All published in June 2000. As Swanson reflected, this group had developed a sense of solidarity and camaraderie, having 
previously put together a successful public communication document-glossy and with eyecatching diagrams - that was a departure from the standard, bureaucratic reports they had all produced for many years.37

These insights into the real world of policy making are an important reminder that an analytic focus on the content of global conferences would risk obfuscating their real function, namely to manufacture consent through ritualistic enactment. Moreover, although most of those present remain excluded from actual policy making, they nonetheless perform important roles. Little observed this during the Earth Summit:

By writing only about the event as conceived of and presented by the United Nations, observers are implicitly accepting the official version that this is 'the event' worthy of scrutiny, while the numerous other (non)events should best be ignored or forgotten. Such a limited treatment of the process also tends to highlight the 'show' or performative side of the process.38

Applying this theoretical framework to social media coverage of current global conferences, we must ask whether social media perform similar affirmative, discourse- reinforcing roles or, either alternatively or concurrently, create virtual spaces of agency in which these discourses can be scrutinised. Data generated by social media in the context of one of the major development conferences of the recent past can help us answer this question.

\section{Social media content as data}

Blogs are chronologically arranged posts to web pages, usually focusing on a single subject, and updated by an individual or organisation. Twitter, Inc is an online service provider for micro-blogging. Similar to blogging in that it allows an individual ('tweeter') to share thoughts or interesting news stories, it is called 'micro-blogging' because it limits users to 140 characters per message. Individuals with a Twitter account can create messages called 'tweets'. When a tweet is sent, it reaches the sender's 'followers', meaning anyone who has agreed to receive the sender's tweets by way of a free subscription to the sender's account. A network of followers, therefore, could be as small as a few friends or as large as the more than 11 million followers receiving pop star Lady Gaga's tweets.39 In June 2011 Twitter reported that its users were sending 200 million tweets per day.40 In addition to sending personal status updates, Twitter also allows users to assign labels to particular content called 'hashtags', as well as to 're-tweet' messages sent by others. Hashtags allow Twitter users to label the subject of their message by adding the \# symbol to a specific keyword of their choosing, such as \#MDG. 'Re-tweeting' is similar to forwarding an e-mail; it gives users the ability to retransmit information, ideas or breaking news to their followers. Re-tweeting is a tool often used to generate social action and to disseminate information to a network of individuals quickly.41 This connectivity of individuals by linking networks has the ability to spread information within minutes or even seconds, a phenomenon that lies at the heart of global social networking.

In order to capture social media coverage of the MDG Summit, we began the content search in a convenient sample of 24 blogs that we considered frequent producers of commentary on global development issues. As most blogs have lists of hyperlinks to other 
'favourite' blogs, 10 new blogs were added to this list during the process, thus enlarging our sample to 34 blogs. We then followed snowballing sampling strategy for blog research,42 mindful that this approach may not guarantee a representative sample. However, snowballing in social media analysis, according to Browne 'avoids the problems associated with methods that rely on the categorization of groups'.43 Consistent with post-positivist approaches to ensuring empirical validity, 44 we also circulated our complete list of blogs covered among fellow bloggers and received affirmative feedback with respect to its scope. We then ran basic keyword searches for entries posted in each blog between 15 July and 15 November 2010. Search terms included 'Millennium Summit', 'MDG Summit', 'Millennium Development Summit', 'MDG', and 'UN Summit NEAR MDG' (the latter being a Boolean search term). After collecting all relevant entries, we used the qualitative analysis software NVivo to create discursive nodes in order to capture the context in which specific terms were used frequently. The results are outlined and visualised further below.

We approached the Twitter component by identifying appropriate search engines for harvesting archived tweets. This initial search rendered only one suitable search engine (www.topsy.com) because it was able to move beyond real-time analysis, allowing for a collection of messages sent several months previously. Search engines such as www.google.com had recently discontinued their Twitter search capabilities for public users, while subscription software such as www.discovertext.com only permits collection as far back as 30 days. Inquiries with the Library of Congress (LOC) in Washington, DC helped clarify that these restrictions were probably the result of Twitter, Inc's decision to donate its tweets archive to LOC. LOC began indexing the data in 2011 and has recently begun to release some of the data for public use, but this was not timely enough for us to use these data as the basis for this study. We therefore relied on data provided by www.topsy.com. We performed searches using the hashtag \# MDG for each hour of the three days during which the Summit took place, starting at 9 am on 20 September 2010 and concluding at 8 pm on 22 September 2010, generating a total of 3007 hits: 1162 on the first day, 843 on the second, and 1002 on the third.

Some limitations affecting the tweet research component could not be avoided. For the hours between $1 \mathrm{pm}$ and $2 \mathrm{pm}, 2 \mathrm{pm}$ to $3 \mathrm{pm}$, and $5 \mathrm{pm}$ to $6 \mathrm{pm}$ EST on each of the three days the searches on www.topsy.com yielded a total of 10 pages each. Since hour windows are the shortest possible timeframe and the maximum number of pages that can be accessed for each search was 10 , there was no method of verification accessible to us that could prove whether the search would have yielded more hits than those that could be viewed on the 10 pages generated by the software. However, since our complete Twitter dataset consists of tweets collected during 59 separate hours, we are confident that the effect of potential imprecision during nine of these 59 slots on our overall sample is small.

\section{Results}

Blogging analysis

Our review of 34 blogs rendered a total of 108 relevant blog entries written by a total of 29 bloggers: 16 are men, 13 are women, and four are collaborative entries. One blog lists no author, which is not uncommon in the development blogosphere. The number of relevant entries per blog ranges from one to 14 . Bloggers with established ties to the global 
This is a pre-print version

The final version of the article is published in:

Third World Quarterly, 2013, Vol. 34, No.3, 405-422,

http://dx.doi.org/10.1080/01436597.2013.784607

development industry dominate the upper half of the frequency ranking. Table 1 provides an overview of this distribution and of the blogs most relevant to the MDG Summit. Mark Leon Goldberg and Alanna Shaikh are affiliated with the independent UN news website, UN Dispatch. Duncan Green was the Head of Research for

Table 1. Overview of most relevant blogs (number of entries relevant to 2010 MDG Summit)

Blogger No. of entries Collaborative entries URL

Mark Leon Goldberg

Tom Paulson

Duncan Green

Lawrence Haddad

Alanna Shaikh

Linda Raftree

Laura Freschi
14

13

10

2, with Matt Davies and

Sam Bickersteth

7

7

7

5 www.undispatch.com

http://humanosphere.kplu.org www.oxfamblogs.org

www.developmenthorizons.com

www.unidispatch.com;

http://endtheneglect.org;

http://bloodandmilk.org

http://lindaraftree.wordpress.com

http://aidwatchers.org

Oxfam International. Tom Paulson is a radio host at Seattle's KPLU. Lawrence Haddad is the Director of the Institute of Development Studies at the University of Sussex. Laura Freschi either blogged independently or together with William Easterly out of the Development Research Institute at New York University. Linda Raftree works for PLAN USA. Blogger Laura Seay (http://texasinafrica.blogspot.com) stood out because she was frequently referred to in other blogs. In her own blog she lists many entries related to the Summit, thus highlighting the importance of 'curating' a virtual archive in the blogosphere. Epitomising the 
spirit of referentiality across blogs, Laura Seay mentions another blogger's suggestion for organising a 'TedXPoor' event, a sarcastic reference to TedX, a highly popular conference series on global affairs that is videotaped and then streamed on the web, but which has been criticised for perpetuating an 'apolitical, techno-optimist' culture of development.45 Tom Paulson and Laura Seay also offered a critical view of other bloggers' entries.

We conducted a content analysis in NVivo in order to identify salient themes and issues. The analysis was based on both manual and computer coding. Keywords such as 'aid', 'future', 'gender', 'measurability' and 'South' were first coded as simple nodes, based on keyword searches, and later linked to other simple nodes, thus creating so-called tree nodes, which act as umbrella terms or categories. Figure 1 depicts the six tree nodes ('measurability', 'gender', 'government', 'MDGS', 'aid' and 'attitude'). Textual proximity in the dataset defined the parenting relationship in which each tree node is a parent to keywords with which it is closely associated. Three additional keywords ('future', 'Africa' and 'Sachs') also appeared frequently and were therefore listed as well, but they stood in no clear association with other nodes. They were thus categorised separately, bearing the potential of becoming tree nodes in their own right at a deeper level of analysis.

'Aid' was frequently linked to calls for increased 'donor' attention (51 times) or 'funding' (43), to the fulfilment of the promise for 'change' (72) on US President Barack Obama's part (63), and on the part of the 'UK' (46), as well as to
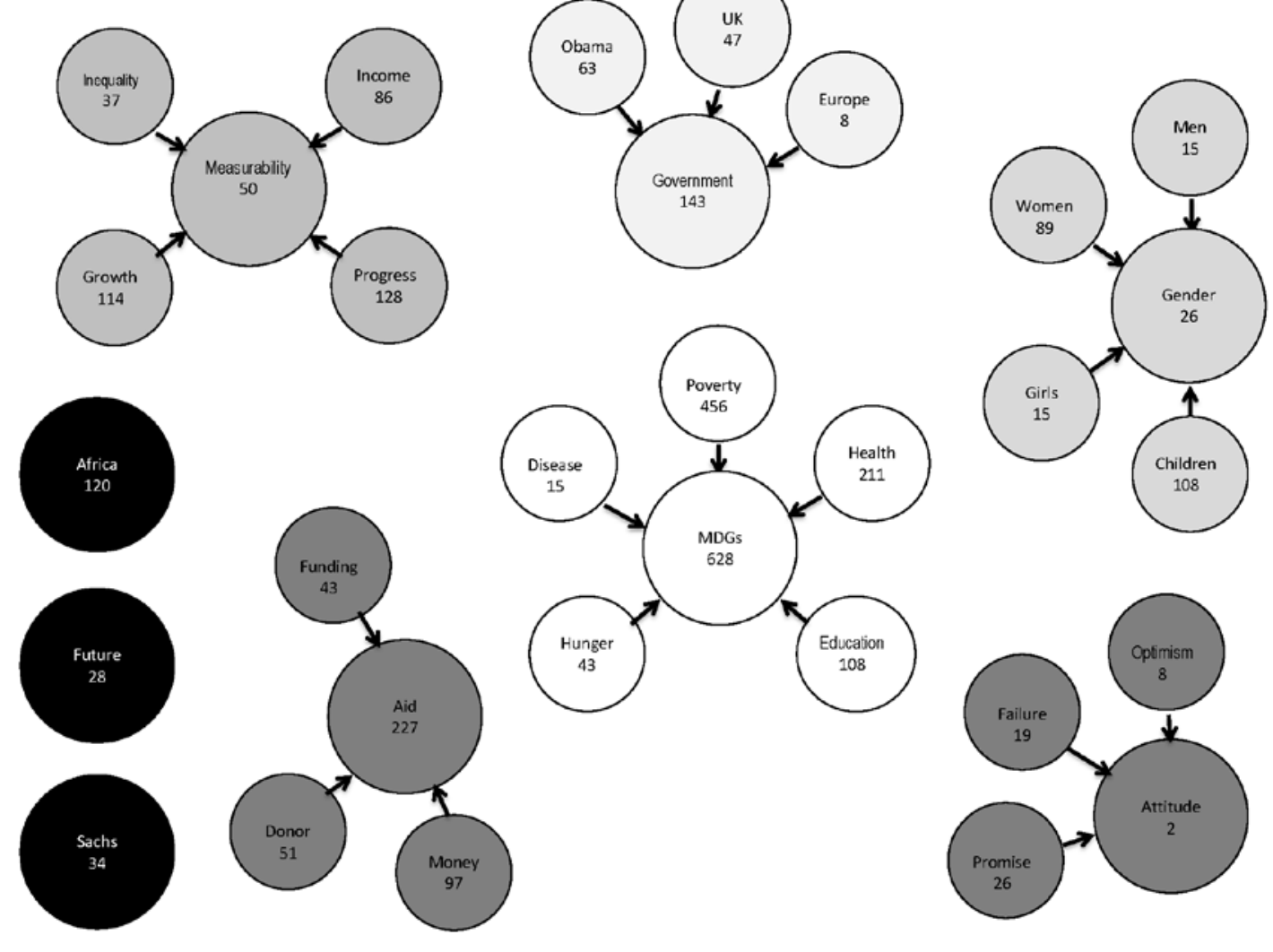

FIGURE 1. Tree nodes of blog content on the 2010 MDG Summit (108 blog entries). 
former US President Bill Clinton's (37) and philanthropist Bill Gates's (42) efforts to raise awareness and increase donations toward the MDGS. As depicted in Figure 1, the tree node 'attitude' is a category label that acts as a tree node linked to simple nodes through word searches performed by proxy. Bloggers' 'attitude' was dominated by a general sense that the MDGs were far from being fulfilled, in addition to calls for a change in international strategy through increased 'accountability' (58) and 'transparency' (37). The MDGs are considered a 'promise' (32) that has 'failed' (19) to be realised, therefore necessitating reinvigorated 'commitment' (24). The keyword 'future' appeared 28 times in the dataset and also acts as a tree node for terms that reflect a concern for the direction in which donors, the private sector and the US and British governments will be taking their efforts toward meeting the MDGs. 'Gender' occurred 28 times and could be linked to two other frequently used terms, namely 'children' (108) and 'women' (89). The dominant focus on women and children was highlighted in contrast to the node 'men', which only occurred five times in the dataset.

The MDGS themselves were linked closely to 'poverty' (456), 'health' (211), 'education' (108), 'hunger' (43) and 'water' (25). With regard to health, the simple nodes under this umbrella were 'AIDS' (18), 'HIV' (16) and 'malaria' (16), indicating the diseases which have received the greatest amount of political attention and resources during the past decade, despite the fact that other causes of ill health are not only more lethal on a global scale, but also can be more effectively treated.46 Another tree node representing a key issue in relevant blog entries was 'measurability' (50), associated most commonly with 'progress' (128), 'growth' (114) and 'income' (86). Bloggers also mentioned measurability in the context of 'impact' (57), 'outcomes' (35) and 'results' (29). Finally, the geographic foci that emerged clearly linked the MDGS to locations in the Global 'South' (20). However, 'Africa' as a standalone term occurred 120 times in the dataset, eclipsing all other developing regions. Indeed, specific names of African countries, such as 'Ethiopia' (18), 'Tanzania' (11), 'Ghana' (10) and 'Congo' (4), were each associated more often with the Summit than were references to the entire Latin American region.

\section{Tweet analysis}

Our content analysis of the 3007 tweets indicated that key issues raised in the tweets related to education, children, maternal health, world leaders, the reduction of Canada's development aid, speeches by the prime ministers of the UK and Australia, the World Bank, the G20, hunger, TedxChange, former US President Bill Clinton, China, Bolivian President Evo Morales, print media websites (in particular the UK newspapers Guardian and Financial Times), links to UN strategy reports and links to individual blogs and video clips. Judging by the Twitter account name, the overwhelming majority of tweeters active in the context of the MDG Summit appeared to be either organisations' communication units or individuals directly affiliated with such organisations. These prominently included accounts registered by international NGOs, for instance@AmnestyOnline, @Oxfam or @savethechildren. The most active individual tweeter-Adrian Lovett at Save the Children-sent 22 tweets during the three day event. The two second most active non-organisational accounts dropped off significantly compared to Lovett's activity: UNDP Administrator Helen Clark and Michael Shapcott, a Canadian academic, each sent four related messages. Table 2 provides an overview of the most active non-organisational Twitter accounts relating to the 2010 MDG Summit. 
This is a pre-print version

The final version of the article is published in:

Third World Quarterly, 2013, Vol. 34, No.3, 405-422,

http://dx.doi.org/10.1080/01436597.2013.784607

\begin{abstract}
Although some of the bloggers (for example, Laura Seay) are also mentioned in the tweets, traditional media as reference points featured more prominently in them, for instance Jeffrey Sachs's op-ed in the Financial Times blog.47 Given the 140 character limit, quotations by government representatives and prominent public figures were (re)tweeted frequently. Examples include 'Dutch aid minister says the top three answers to education crisis are “teachers, teachers, teachers”' (@adrianlovett) or ‘@QueenRania: We have 1 goal—to give children [sic] w/ no voice \& no hope the chance to realize their 1 goal-to go to school' (retweeted-RT- by @cfpdx). Such informational or motivational tweets were complemented-although to a lesser extent-by what one might call 'vanity tweets', which mainly cite the names of government officials or other public figures, arguably as a signal that the tweeter considers herself to be part of the epistemic community of international development. The latter observation also underlines the main difference between the results of our blog analysis and our subsequent analysis of tweets: Twitter is used
\end{abstract}

Table 2. Top non-organisational Twitter messages during the 2010 MDG Summit

\title{
Adrianlovett (22)
}

http://t.co/PUhaiH5

http://youtu.be/5H2Nlq49V2c

Nthabiseng Tshabalala

My \#mdg blog 1: just off plane http://bit.ly/cMzKRz

Ex UK PM Gordon Brown says he is 'angry but inspired' about children out of school

Me and Nthabiseng Tshabalala at the \#1goal event today http://twitpic.com/2qe9la

Dutch aid minister says the top 3 answers to education crisis are "teachers, teachers, teachers"

RT @benhewittindia: India to be "shining example" on MDGs - but not on mothers and children:

http://toi.in/c3i9bq

Aussie ex-PM Kevin rudd says education is critical to reducing child mortality

4 hrs to our big moment in Grand Central. Will we reach 3m people?

1goal event underway. World bank promising to shift $\$ 750 \mathrm{~m}$ into schools. It's a start...

VIDEO "We're going to do our bit" UK minister tells Sian http://t.co/c3oSfUP

Team Save the Children cooking up a little idea for tomorrow when leaders agree their child health strategy watch this space

Me and Claire Danes: could we get any closer? http://twitpic.com/2qglr8

Save the Children is making its own commitment to saving children's lives. We will invest \$2bn - with your help The big strategy on health is out. Big commitments and this only happened because millions called for action.

Now for delivery

VIDEO Now this is good. Who is that masked man delivering a tasty message to world leaders?

http://bit.ly/d4mRpE

Thank you @mummytips for helping us make our lovely energy bars http://twitpic.com/2qx49h

Watch UN strategy launch in $1 \mathrm{hr}$ from now - http://bit.ly/9BSbBJ (choose channel 4). This wouldn't be

happening without you!

Here's the UN announcement of the Global Strategy for Women just out http://bit.ly/b4aJg6

VIDEO See my attempts to hand out energy bars at UN Summit. Msg to leaders: RUN DON'T WALK

http://bit.ly/aEc7kw

Wen, Meles and now Stoltenberg speaking at UN mother and child health event.

helenclark-undp (4)

I'm @ the \#MDGSummit, with the Global Leaders Council for Reproductive Health. Did you know that 1

\#MDG concerns maternal health?

I'm @ the \#MDGSummit making opening remarks at the Spanish \#MDG Achievement Fund \#SocialJustice. 
This is a pre-print version

The final version of the article is published in:

Third World Quarterly, 2013, Vol. 34, No.3, 405-422,

http://dx.doi.org/10.1080/01436597.2013.784607

Where there is strong leadership, an absence of conflict, sufficient capacity \& funding for development, there will be \#MDG progress

Just discussed \#MDG progress in Latin America with President of Bolivia Evo Morales

Michael-shapcott (4)

OECD reports Canada well below both UN target and int'l avg on official development assistance http://bit.ly/baoKV3

Does Canada deserve a seat at UN Security Council, considering our shrinking international development profile? http://bit.ly/bzyppa

Shocking \#MDG facts on Canada: Aid spending down, UK spends $50 \%$ more per person than Cda, military gets 4x more http://bit.ly/aoSaTs

RT²@Oxfam: Day 1@ \#MDG \#UNSummit: Millennium Development Goals: Will world leaders stand up, or hit snooze button?

\section{Asteris (3)}

RT @guardiannews UN: Corporate lobbying is blocking food reforms http://bit.ly/chjo2N \#MDG

RT @texasinafrica What's missing in this week's \#MDG conversations http://bit.ly/aSRYqt "western thinking abt development is elite-driven"

RT @AmnestyOnline \#MDG Summit: World leaders fail to uphold rights of the poorest http://bit.ly/dzUoAt

Summits aren't enough, @UN

\section{Cfpdx (3)}

@QueenRania: "We have 1 goal --to give childen w/ no voice \& no hope the chance to realize their 1 goal --to go to school." \#saveMDG \#mdg

Melinda Gates: Recession pressured global efforts | Beyond Binary - CNET News \#TEDxChange \#MDG http://post.ly/yoi7

From Clinton Global Initiative to the U.N. Summit, philanthropy goes into overdrive this week - \#CGI2010 \#MDG... http://ff.im/qRoj2

Jeffdsachs (3)

RT @EndOfPoverty: Did you know you can watch the \#MDG Summit live via webcast? http://bit.ly/bjdKsc

RT @anujkp: \#MDG Jeffrey Sachs' blog on FT re: \#Bhutan PM's address in UN GA. http://bit.ly/bthi7N

FT blog: China's performance at the UN summit is extraordinary... \#MDGSummit \#UNweekDML \#MDG http://bit.ly/dwF7gl

\section{Milieunet (3)}

UNEP Report : Green Economy can Reduce Poverty and Help Meet Millennium Development Goals http://bit.ly/9rQ6MI \#MDG

Stand Up Against Poverty 2010 http://bit.ly/bSD8lM

TEDxChange 2010: Melinda French Gates about the Millennium Development Goals http://bit.ly/dlpt2K

\section{mjw-alexander (3)}

Lots of excitement at France's announcement at the \#mdg summit that they will focus on a financial transaction tax for the G20

First day of \#mdg summit and @actionaid ceo is speaking about women and hunger. Lets hope world leaders listen

Great @guardian blog following the \#mdg summit live at http://tinyurl.com/2cbnrvk

${ }^{1}$ Number in brackets denotes total count of tweets sent during the event by this Twitter user

${ }^{2} \mathrm{RT}=$ retweeted by this Twitter user

almost entirely as a broadcasting tool. Overall, tweets were used primarily by members of the epistemic community to share third-party content rather than to establish an online presence or a distinctive digital identity for individuals or organisations. 


\section{Discussion}

Social media as 'ideas space', as Oxfam blogger Duncan Green has called the blogosphere,48 had rather little to add to traditional notions of epistemic communities in the context of the 2010 MDG Summit. Social media involvement during the Summit mainly came in the form of event updates, not as a catalyst of changes with respect to how the event was portrayed, discussed or criticised. It also seems doubtful that social media contributed in ways indicated by earlier research on epistemic communities and their gatherings. Networking or selfmarketing, 49 the normalisation of new terms,50 and the impact of online information flows on 'offline' physical professional spaces, 51 appear inapplicable to the context of global conferences. With reference to Rothenbuhler's ritual theory framework,52 we therefore argue that traditional, pre-digital conference rituals are still very much alive in the digital age. Three important aspects of this claim are highlighted in the following.

\section{Rituals and physicality}

Even though virtual space is potentially without borders, the analysis of blogs and Twitter suggests that there is still a strong physical community element that played a role during the Summit. Many of the bloggers and some of the institutional Twitter users were located in New York during the event and arranged 'meet-ups'/'tweet-ups'. For instance, in her blog entry from 18 September 2010, New York University Professor Karen Grepin mentions an event organised in New York on 21 September 2010 and defined as a 'Meet-up of tweeters working on international development, ICT4Development and related areas who are in NYC on 21 September'.53 The link also provides a list of all attending tweeters. While social media thus accompanied the actual event in New York City, the MDG Summit remained a de facto 'invited space', which potentially also explains why there were only a few contributions from outside the 'Northern' development community. This underscores how powerful the ritual space of world conferences still is and that, in this regard, little has changed since the $\begin{array}{lllll}\text { Earth } & \text { Summit } & 20 & \text { years }\end{array}$

\section{Rituals and discourses}

The Twitter content analysed in this study suggests that the theme of the Summit was widely considered incontestable,54 which may explain why few individuals not affiliated with development organisations tweeted on the event. Nevertheless, while one might be tempted to dismiss the Summit on this basis, this stance would miss an important point highlighted by Rothenbuhler:

Many critics of ritual make the mistake of expecting rites and ceremonies to be indicative. Judged that way, many of them are obviously false - they do not accurately describe the world in which they occur. But viewed as timeouts from the usual constraints of practical affairs, they are occasions for imagining how things could be or evaluating how they ought to be.55

The Summit and the MDGS more generally, therefore, lend themselves to discursive analysis. Global performances such as summits exercise a particular 'disciplinary power', which creates and reinforces boundaries of international relations practices that are delineated linguistically in order to privilege certain interpretations over others.56 Such performances are 'about placing individual subjects in regimented/regulated systems and locales'.57 The MDG Summit drew affluent and mobile visitors to the city and 'made' them participate in 
side events and share information on presentations by public figures with an interest in international development. It did so not through coercion but by creating opportunities for reliving learned practices.58 'Ritualized agents do not see themselves as projecting schemes', as Bell reminds us, 'they see themselves only acting in a socially instinctive response to how things are'.59 Five years before the official MDG deadline, the Summit did not aim to introduce new ideas or terms that needed to be discussed in the epistemic community or create a marketplace for individual experts, organisations or academics to present 'new' work. Anchored in traditions, the Summit also did not present an opportunity that encouraged contestation or support.

\section{Rituals and practice}

Performing the MDG Summit to strengthen the MDGS as a 'vehicle that presently dominates global discussions about poverty eradication’ appeared to be successful, 60at least according to official statements by international politicians and diplomats. As our Twitter analysis shows, TedX events were one form of communication outside the official performance, but these events were essentially performed within the accepted conventions of critical engagement. In fact, critical blog posts appear to be virtual extensions of what Rothenbuhler has described as 'ritually structured conflict' in 'anti-institutional events': 'Sit-ins, protest marches, burning effigies, verbal threats, chanting and so on, are all performances patterned to symbolically effect the serious life'.61 Working papers and blog posts thus become virtual representations of how the community can influence the Summit symbolically.

\section{Conclusion}

Global conferences as central components of contemporary global governance are ritualised spaces in which global culture is reproduced by virtue of individual as well as institutional performances. Our research on site-specific processes in the digital age confirms that emerging international development policies continue to be framed 'offline', with very limited input provided through social media. For those concerned about a democratic deficit in international policy making,62 our findings are therefore sobering. The hope that social media might make a significant contribution towards global democratic participation in agenda setting was not fulfilled by social media content generated during the MDG Summit.63 While the epistemic community framing international development policies today is larger, and communication about it is faster and in theory also more open, this process continues to be shaped by what Mosse has termed 'professionalist' dynamics.64 In his embedded research in development organisations he detected 'a professional habitus [which] automatically transferred the actuality of events into the preconceived categories of legitimate meaning and ideal process: "decisions taken democratically by the committees", relationships denuded of power/interest, the power-free flow of information, or the absence of pressure on staff to meet targets'.65 While the use of social media in development projects may indeed catalyse positive change in specific settings,66 global dynamics of how international development is conceived and defined do not seem to be affected by social media to any significant degree. In essence, then, while members of this epistemic community actively take part in the ontological dynamic, the community itself remains as exclusive as ever. Or, in blogger Laura Seay's tweeted words: ‘So ends a day of listening to rich people talk 
about ways to help poor people they'd never dream of letting in the door'.

\section{Notes}

We thank the School of International Service's Dean's Office for supporting this project financially. We also gratefully acknowledge feedback on recent developments in Twitter research offered by Melissa Hire at the US Library of Congress and Tom Emerson at topsy.com. Cora Lacatus provided excellent research assistance and went out of her way to help bring the working paper to a timely completion. Carl-Gustav Anderson, Jed Byers, Emily Edgecombe, Eric Eggleston and Trish Ward copy-edited subsequent versions of the manuscript.

1 See, for example, H Farrell \& D Drezner, 'The power and politics of blogs', Public Choice, 134(12), 2008, pp 15-30; R Maratea, 'The e-rise and fall of social problems: the blogosphere as a public arena’, Social Problems, 55(1), 2008, pp 139-160; and B Etling, J Kelly, R Faris \& J Palfrey, 'Mapping the Arabic blogosphere: politics and dissent online', New Media \& Society, 12(8), 2010, pp 1225-1243.

2 A Breuer, The Role of Social Media in Mobilizing Political Protest: Evidence from the Tunisian Revolution, Bonn: German Development Institute, 2012; PN Howard \& MR Parks, 'Social media and political change: capacity, constraint, and consequence’, Journal of Communication, 62(2), 2012, pp 359-362; C Shirky, 'The political power of social media technology, the public sphere, and political change', Foreign Affairs, January/February, at http://www.foreignaffairs.com/articles/67038/clayshirky/the-political-power-ofsocial-

media; and S Aday, H Farrell, M Lynch, J Sides, J Kelly \& E Zuckerman, Blogs and Bullets: New Media in Contentious Politics, Washington, DC: United States Institute of Peace, 2010.

3 D Shiffman, 'Twitter as a tool for conservation education and outreach: what scientific conferences can do to promote live-tweeting', Journal of Environmental Studies and Sciences, 2(3), 2012, pp 257262.

$4 \mathrm{~K}$ Weller, E Dröge, C Puschmann, 'Citation analysis in Twitter: approaches for defining and measuring information flows within tweets during scientific conferences', in M Rowe, M Stankovic, A Dadzie \& M Hardey (eds), 'Making sense of microposts (\#MSM2011)', workshop at Extended Semantic Web Conference (ESWC 2011), Crete, pp 1-12; C Ross, M Terras, C Warwick \& A Welsh, 'Enabled backchannel: conference Twitter use by digital humanists', Department of Information Studies, University College London, at http://www.ucl.ac.uk/infostudies/Claireross/Digitally_Enabled_Backchannel.pdf; M Ebner \& W Reinhardt, 'Social networking in scientific conferences-Twitter as tool for strengthening a scientific community', Proceedings of the 1st International Workshop on Science 2.0 for TEL at the 4th European Conference on Technology Enhanced Learning (EC-TEL’09), 2009, at http://stellarnet.eu/science2ectel/Home; and W Reinhardt, M Ebner, G Beham \& C Costa, 'How people are using Twitter during conferences', in V HornungPrähauser \& M Luckmann (eds), Creativity and Innovation Competencies on the Web, Proceeding of 5th EduMedia Conference, Salzburg: Salzburg Research, 2009, pp 145-156.

5 D McKenzie \& B Özler, 'The impact of economics blogs', Development Impact (blog), 5 August 2011, at http://blogs.worldbank.org/impactevaluations/node/621, accessed 21 June 2012.

6 H Thörn, 'Global civil society and de-/democratization: AIDS politics, anti-apartheid and the World Social Forum’, Development Dialogue, 49(1), 2007, pp 159-169.

7 Ibid, p 169.

8 United Nations, Programme, 2010, at http://www.un.org/en/mdg/summit2010/programme.shtml, accessed 21 June 2012. 
This is a pre-print version

The final version of the article is published in:

Third World Quarterly, 2013, Vol. 34, No.3, 405-422,

http://dx.doi.org/10.1080/01436597.2013.784607

9 United Nations, 'High-level plenary meeting on the millennium development goals: a compilation of partnership events and action commitments', 2010, at http://www.un.org/en/mdg/summit2010/pdf/HLPM_Side

\%2520events_CRP.pdf, accessed 21 June 2012.

10 United Nations, 'UN summit concludes with adoption of global action plan to achieve development goals

by 2015', 2010, at http://www.who.int/pmnch/media/membernews/2010/20100922_un_closingpr.pdf, accessed 21 June 2012.

11 United Nations, Keeping the Promise: United to Achieve the Millennium Development Goals, United

Nations General Assembly, A/RES/65/1, at http://www.un.org/en/mdg/summit2010/pdf/outcome_documentN1051260.pdf, accessed 21 June 2012.

12 USUN, 'Remarks by President Barack Obama at the millennium development goals summit', 2010, at http://usun.state.gov/briefing/statements/2010/ 147593.htm, accessed 7 July 2011.

13 DFID, 'Speech by Deputy Prime Minister Nick Clegg at the United Nations millennium development goals summit', 2010, at http://www.dfid.gov.uk/Media-Room/NewsStories/2010/Deputy-Prime-Minister-Nick-Cleggs-speech-to-the-UN-General-Assembly/, accessed 21 June 2012.

14 United Nations. 'Statement by HE Mr Sergey Lavrov, Minister of Foreign Affairs of the Russian Federation', 2010, at http://www.un.org/en/mdg/summit2010/debate/RU_en.pdf, accessed 21 June 2012.

15 United Nations, 'Statement by HE Mr SM Krishna Minister of External Affairs of India', 2010, at http://www.un.org/en/mdg/summit2010/debate/IN_en.pdf, accessed 21 June 2012.

16 United Nations, 'Towards the attainment of the millennium development goals: statement by HE Wen Jiabao, Premier of the State Council of the People's Republic of China', 2010, at http://www.un.org/en/mdg/summit2010/debate/CN_en.pdf, accessed 21 June 2012.

17 United Nations, Statement by HE Marcia Helena Carvalho Lopes, Minister for Social Development and the Fight Against AIDS', 2010, at http://www.un.org/en/mdg/summit2010/debate/BR_en.pdf, accessed 21 June 2012.

18 T Paulson, 'Melinda Gates impatiently optimistic at the UN anti-poverty summit', Humanosphere (blog), 2010, 24 September, at http://humanosphere.kplu.org/2010/09/melinda-gates-impatientlyoptimistic-at-theun-anti-poverty-summit/, accessed 21 June 2012.

19 R Abdulla, 'Queen Rania speaks at the MDG summit in New York', 2010, at http://www.queenrania.jo/media/speeches/queen-rania-speaks-mdg-summit-new-york, accessed 21 June 2012.

20 P Guest, 'MDG interview: Jeffery Sachs', This is Africa (blog), 22 September 2010, at http://web.thisisafricaonline.com/News/MDG-Interview-Jeffrey-Sachs, accessed 21 June 2012.

21 K Arsenault, 'September 2010 MDG summit: 13 minutes you just can't miss', One (blog), 18 November 2010, at http://one.org/blog/category/september-2010-mdg-summit/?aux=36, accessed 21 June 2012.

22 N Long, 'Contesting policy ideas from below', in M Bøås \& D McNeill (eds), Global Institutions and Development: Framing the World?, London: Routledge, 2004, pp 24-40.See also M Bøås \& D McNeill, Multilateral Institutions: A Critical Introduction, London: Zed Books, 2003.

23 Bøås \& McNeill, Global Institutions and Development; and D Mosse, Cultivating Development: An Ethnography of Aid Policy and Practice, London: Pluto Press, 2005.

24 R Harper, Inside the IMF: An Ethnography of Documents, Technology and Organisational Action, London: Academic Press, 1998; and D Mosse \& D Lewis, The Aid Effect: Giving and Governing in International Development, London: Pluto Press, 2005.

25 D Mosse, 'Introduction: the anthropology of expertise and professionals in international development', in D Mosse (ed), Adventures in Aidland: The Anthropology of Professional 
This is a pre-print version

The final version of the article is published in:

Third World Quarterly, 2013, Vol. 34, No.3, 405-422,

http://dx.doi.org/10.1080/01436597.2013.784607

International Development, Oxford: Berghahn Books, 2011, pp 1-31; and A Fechter \& H Hindman, Inside the Everyday Lives of Development Workers: The Challenges and Futures of Aidland, Sterling, VA: Kumarian Press, 2011.

26 C Chabbott, 'Constructing educational consensus: international development professionals and the world conference on education for all', International Journal of Educational Development, 18(3), 1998, pp 207-218.

27 See also M Schechter, United Nations-sponsored World Conferences: Focus on Impact and Follow-up, Tokyo: UNU Press, 2001.

28 United Nations, United Nations Global Conferences: What have they Accomplished?, New York: UN Department of Public Information, 1998.

29 P Little, 'Ritual, power and ethnography at the Rio Earth Summit', Critique of Anthropology, 15(3), 1995, pp 265-288.

30 Ibid.

31 F Lechner \& J Boli, 'Constructing world culture', in Lechner \& Boli (eds), World Culture: Origins and Consequences, Oxford: Blackwell, 2005, pp 81-108.

32 E Rothenbuhler, Ritual Communication: From Everyday Conversation to Mediated Ceremony, London: Sage, 1998, p 27.

33 R Bauman, 'Performance', in E Barnouw (ed), International Encyclopedia of Communications, Vol 3, New York: Oxford University Press, 1989, pp 262-266.

34 Lechner \& Boli, ‘Constructing world culture', p 102.

$35 \mathrm{~J}$ Vandemoortele, 'Can the MDGS foster a new partnership for pro-poor policies?', in J Brinkerhoff, S Smith

\& H Teegen (eds), NGOs and the Millennium Development Goals: Citizen Action to Reduce Poverty, London: Palgrave Macmillan, 2007, pp 23-48.

36 D Hulme \& S Fukuda-Parr, International Norm Dynamics and 'the End of Poverty': Understanding the Millennium Development Goals (MDGS), BWPI Working Paper 96, Manchester: Brooks World Poverty Institute, 2009.

37 Ibid, p 16.

38 Little, 'Ritual, power, and ethnography at the Rio Earth Summit', p 286.

39 'Top 100 twitaholics based on number of followers', at http://twitaholic.com/, 2011, accessed 21 June 2012.

40 '200 million tweets per day', Twitter Blog, 30 June 2011, at http://blog.twitter.com/2011/06/200milliontweets-per-day.html, accessed 21 June 2012.

41 D Boyd, S Golder \& G Lotan, 'Tweet, tweet, retweet: conversational aspects of retweeting on Twitter', in Proceedings of the Forty-Third Hawai'i International Conference on System Sciences, Kauai, HI, 6 January 2010.

42 D Li \& G Walejko, 'Splogs and abandoned blogs: the perils of sampling bloggers and their blogs', Information, Communication \& Society, 11(2), 2008, pp 279-296.

$43 \mathrm{~K}$ Browne, 'Snowball sampling: using social networks to research non-heterosexual women', International Journal of Social Research Methodology, 8(1), 2005, pp 47-60.

44 J Creswell \& D Miller, 'Determining validity in qualitative inquiry', Theory into Practice, 39(3), 2000, pp 124-130.

45 T Foremski, 'The “Golden Arches” of TED and the rise of the techno-humanists', 2012, at http://www.zdnet.com/the-golden-arches-of-ted-and-the-rise-of-the-techno-humanists-7000002076/, accessed 21 September 2012.

46 DE Esser, 'More money, less cure: why global health assistance needs restructuring', Ethics \& International Affairs, 23(3), 2009, pp 225-234.

47 JD Sachs, 'China's performance at the UN summit is extraordinary', Beyondbricks (blog), 22 September 2010, at http://blogs.ft.com/beyond-brics/2010/09/22/jeffrey-sachs-extraordinarychina/\#axzz1Re6UbSGe, accessed 21 June 2012. 
48 D Green, 'Is the blogging bubble about to burst?', From Poverty to Power (blog), 15 June 2011, at http://www.oxfamblogs.org/fp2p/?p=5790, accessed 21 June 2012.

49 Cf Weller et al, 'Citation analysis in Twitter'.

50 Reinhardt et al, 'How people are using Twitter during conferences'.

51 M Ebner \& W Reinhardt, 'Social networking in scientific conferences'.

52 E Rothenbuhler, Ritual Communication.

53 K Grepin, 'One more reason why living in New York City is amazing', Karen Grepin's Global Health Blog, 18 September 2010, at http://karengrepin.com/2010/09/one-more-reason-why-living-innew-york.html, accessed 21 June 2012.

54 A recent UN Foundation report notes that $89 \%$ of Americans surveyed were not familiar with the MDGS; however, when provided with a brief explanation of each, $87 \%$ of those surveyed said they believe the USA should be very or somewhat involved in trying to achieve the MDGS. These figures are, in part, a reflection of the level to which those surveyed could recall hearing about international events and associating humanitarian involvement with the UN, according to the researchers. The survey by WorldPublicOpinion.org showed a smaller but significant number of Americans (75\%) is willing to pay the estimated individual cost of fully funding the goals. United Nations Foundation, 'United Nations approval rating rises to $60 \%$ in new opinion poll', 2010, at http://www.unfoundation.org/news-and-media/press-releases/2010/united-nations-approval-ratingrises-to-60-percent.html, accessed 21 June 2012; and World Public Opinion.org, 'Publics in developed countries ready to contribute funds necessary to cut hunger in half by 2015', 2008, at http://www.worldpublicopinion.org/pipa/articles/btdevelopmentaidra/554.php?lb=btda\&pnt=

554\&nid=\&id, accessed 22 June 2012.

55 E Rothenbuhler, Ritual Communication, p 15.

56 J George, Discourses of Global Politics: A Critical (Re)Introduction to International Relations, Boulder,

CO: Lynne Rienner, 1994; and T Teivainen, 'The political and its absence in the World Social Forum: implications for democracy’, Development Dialogue, 49(1), 2007, pp 69-79.

57 F Debrix, 'Language, nonfoundationalism, international relations', in Debrix (ed), Language, Agency, and Politics in a Constructed World, London: M. E. Sharpe, 2003, pp 3-25.

58 A Lang, 'Conflicting narratives, conflicting moralities: the United Nations and the failure of humanitarian intervention', in F Debrix (ed), Language, Agency, and Politics in a Constructed World, London: ME Sharpe, 2003, pp 171-195.

59 C Bell, Ritual Theory, Ritual Practice, Oxford: Oxford University Press, 1992, p 206.

60 D Hulme \& S Fukuda-Parr, International Norm Dynamics and ‘the End of Poverty', p 30.

61 E Rothenbuhler, Ritual Communication, p 45.

62 See for example, $\mathrm{H}$ Thörn, 'Global civil society and de-/democratization'.

63 R Dahl, Democracy and its Critics, New Haven, CT: Yale University Press, 1989; and D Held, Democracy and the Global Order: From the Modern State to Cosmopolitan Governance, Cambridge: Polity Press, 1995.

64 D Mosse, 'Introduction', p 22.

65 Ibid.

66 S Schimmelpfennig, 'Tracking the World Vision/NFL shirt donation controversy: Good Intentions are not enough' (blog), 12 February 2011, at http://goodintents.org/aid-debates/world-vision-nflcontroversy,

accessed

24

June

2012.

\section{Notes on Contributors}

Tobias Denskus (Email: tobias@aidnography.de) is a senior lecturer in communication for development at Malmö University in Sweden. He received his $\mathrm{PhD}$ from the University of 
This is a pre-print version

The final version of the article is published in:

Third World Quarterly, 2013, Vol. 34, No.3, 405-422,

http://dx.doi.org/10.1080/01436597.2013.784607

Sussex. His research on peace building, organisational ethnography and social media has been published in Evaluation and Program Planning, Development in Practice and Peace \& Change. He blogs at www.aidnography.de.

Daniel E Esser (Email: esser@american.edu) is assistant professor of international development in the School of International Service, American University. His articles have appeared in World Development, the Journal of Modern African Studies, Urban Studies and Environment and Urbanization, among others. He blogs at www.danielesser.org. 